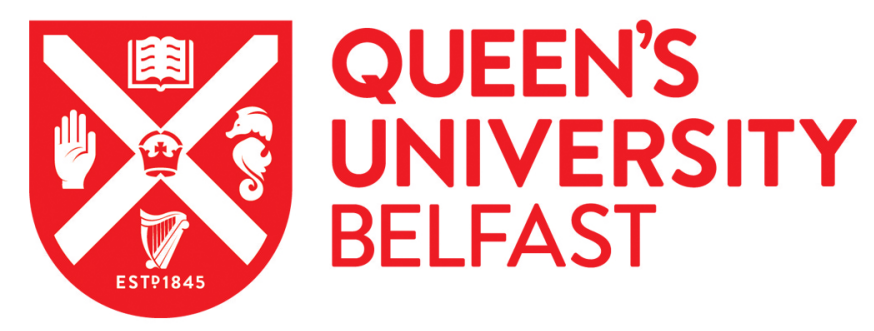

\title{
Spatial allocation of material flow analysis in residential developments: a case study of Kildare County, Ireland
}

Roy, M., Curry, R., \& Ellis, G. (2015). Spatial allocation of material flow analysis in residential developments: a case study of Kildare County, Ireland. Journal of Environmental Planning and Management, 58(10), 1749-1769. https://doi.org/10.1080/09640568.2014.951115

Published in:

Journal of Environmental Planning and Management

Document Version:

Peer reviewed version

Queen's University Belfast - Research Portal:

Link to publication record in Queen's University Belfast Research Portal

Publisher rights

(C) 2014 University of Newcastle upon Tyne

This is an Accepted Manuscript of an article published by Taylor \& Francis in Journal of Environmental Planning and Management, available online: http://dx.doi.org/10.1080/09640568.2014.951115

\section{General rights}

Copyright for the publications made accessible via the Queen's University Belfast Research Portal is retained by the author(s) and / or other copyright owners and it is a condition of accessing these publications that users recognise and abide by the legal requirements associated with these rights.

Take down policy

The Research Portal is Queen's institutional repository that provides access to Queen's research output. Every effort has been made to ensure that content in the Research Portal does not infringe any person's rights, or applicable UK laws. If you discover content in the Research Portal that you believe breaches copyright or violates any law, please contact openaccess@qub.ac.uk. 


\section{PROOF COVER SHEET}

\begin{tabular}{ll}
\hline Author(s): & Manoj Roy, Robin Curry and Geraint Ellis \\
Article title: & $\begin{array}{l}\text { Spatial allocation of material flow analysis in residential developments: a } \\
\text { case study of Kildare County, Ireland }\end{array}$ \\
Article no: & 951115 \\
Enclosures: & $\begin{array}{l}\text { 1) Query sheet } \\
\text { 2) Article proofs }\end{array}$
\end{tabular}

Dear Author,

1. Please check these proofs carefully. It is the responsibility of the corresponding author to check these and approve or amend them. A second proof is not normally provided. Taylor \& Francis cannot be held responsible for uncorrected errors, even if introduced during the production process. Once your corrections have been added to the article, it will be considered ready for publication.

Please limit changes at this stage to the correction of errors. You should not make trivial changes, improve prose style, add new material, or delete existing material at this stage. You may be charged if your corrections are excessive (we would not expect corrections to exceed 30 changes).

For detailed guidance on how to check your proofs, please paste this address into a new browser window: http://journalauthors.tandf.co.uk/production/checkingproofs.asp

Your PDF proof file has been enabled so that you can comment on the proof directly using Adobe Acrobat. If you wish to do this, please save the file to your hard disk first. For further information on marking corrections using Acrobat, please paste this address into a new browser window: http:// journalauthors.tandf.co.uk/production/acrobat.asp

2. Please review the table of contributors below and confirm that the first and last names are structured correctly and that the authors are listed in the correct order of contribution. This check is to ensure that your name will appear correctly online and when the article is indexed.

\begin{tabular}{|l|l|l|l|l|}
\hline Sequence & Prefix & Given name(s) & Surname & Suffix \\
\hline 1 & & Manoj & Roy & \\
\hline 2 & & Robin & Curry & \\
\hline 3 & & Geraint & Ellis & \\
\hline
\end{tabular}


Queries are marked in the margins of the proofs, and you can also click the hyperlinks below.

\section{AUTHOR QUERIES}

\section{General points:}

1. Permissions: You have warranted that you have secured the necessary written permission from the appropriate copyright owner for the reproduction of any text, illustration, or other material in your article. Please see http://journalauthors.tandf.co.uk/permissions/ usingThirdPartyMaterial.asp.

2. Third-party content: If there is third-party content in your article, please check that the rightsholder details for re-use are shown correctly.

3. Affiliation: The corresponding author is responsible for ensuring that address and email details are correct for all the co-authors. Affiliations given in the article should be the affiliation at the time the research was conducted. Please see http://journalauthors.tandf.co.uk/ preparation/writing.asp.

4. Funding: Was your research for this article funded by a funding agency? If so, please insert 'This work was supported by <insert the name of the funding agency in full $>$ ', followed by the grant number in square brackets '[grant number $\mathrm{xxxx}$ ]'.

5. Supplemental data and underlying research materials: Do you wish to include the location of the underlying research materials (e.g. data, samples or models) for your article? If so, please insert this sentence before the reference section: 'The underlying research materials for this article can be accessed at $<$ full link $>$ / description of location [author to complete]'. If your article includes supplemental data, the link will also be provided in this paragraph. See $<$ http://journalauthors.tandf. co.uk/preparation/multimedia.asp $>$ for further explanation of supplemental data and underlying research materials.

6. The CrossRef database (www.crossref.org/) has been used to validate the references. Mismatches will have resulted in a query.

Q1. AU: Please provide the department, if applicable, for affiliations ' $a$ ', ' $b$ ', and 'c'.

Q2. AU: Please check the edit in the sentence "While these assessments of ..." for correctness.

Q3. AU: Please note that the use of "ibid" is against journal style. Please replace these with the relevant reference details throughout.

Q4. AU: Please check the sentence "The coupling of MFA modelling ..." for clarity.

Q5. AU: Please check the sentence "In many respects, therefore, Kildare ..." for correctness.

Q6. AU: Please check the phrase "housing building records" in the sentence "The probability of demolition ..." for correctness.

Q7. AU: Please spell out "GIS" in full at first mention.

Q8. AU: Please spell out "OIS" in full at first mention.

Q9. AU: Please check the phrase " $m_{i}$ above" in the sentence "This gives us the following ..." for correctness.

Q10. AU: Please check the sentence "Interestingly, not until the net ..." for clarity.

Q11. AU: Please check the edit in the sentence "The higher the population/building ..." for correctness. 
Q12. AU: The reference [Ayres, 2004] is listed in the references list but is not cited in the text. Please either cite the reference or remove it from the references list.

Q13. AU: Please provide the page range for "Haberl et al. 2013" references list entry following journal style http://www.tandf.co.uk/journals/authors/style/reference/ tf_ChicagoAD.pdf.

Q14. AU: Please provide the page range for "Hoggart 2003" references list entry following journal style http://www.tandf.co.uk/journals/authors/style/reference/ tf_ChicagoAD.pdf.

Q15. AU: Please provide the publisher location for "OECD 2003" references list entry following journal style http://www.tandf.co.uk/journals/authors/style/reference/ tf_ChicagoAD.pdf.

Q16. AU: Please provide the publisher location for "RoI 2003" references list entry following journal style http://www.tandf.co.uk/journals/authors/style/reference/ tf_ChicagoAD.pdf.

Q17. AU: The reference [Xiang and Clarke | 2003] is listed in the references list but is not cited in the text. Please either cite the reference or remove it from the references list.

Q18. AU: Please provide the volume number and page range for "Zhang 2013" references list entry following journal style http://www.tandf.co.uk/journals/ authors/style/reference/tf_ChicagoAD.pdf. 


\section{How to make corrections to your proofs using Adobe Acrobat/Reader}

Taylor \& Francis offers you a choice of options to help you make corrections to your proofs. Your PDF proof file has been enabled so that you can edit the proof directly using Adobe Acrobat/Reader. This is the simplest and best way for you to ensure that your corrections will be incorporated. If you wish to do this, please follow these instructions:

1. Save the file to your hard disk.

2. Check which version of Adobe Acrobat/Reader you have on your computer. You can do this by clicking on the "Help" tab, and then "About".

If Adobe Reader is not installed, you can get the latest version free from http://get.adobe.com/ reader/.

3. If you have Adobe Acrobat/Reader 10 or a later version, click on the "Comment" link at the righthand side to view the Comments pane.

4. You can then select any text and mark it up for deletion or replacement, or insert new text as needed. Please note that these will clearly be displayed in the Comments pane and secondary annotation is not needed to draw attention to your corrections. If you need to include new sections of text, it is also possible to add a comment to the proofs. To do this, use the Sticky Note tool in the task bar. Please also see our FAQs here: http://journalauthors.tandf.co.uk/production/index.asp.

5. Make sure that you save the file when you close the document before uploading it to CATS using the "Upload File" button on the online correction form. If you have more than one file, please zip them together and then upload the zip file.

If you prefer, you can make your corrections using the CATS online correction form.

\section{Troubleshooting}

Acrobat help: http://helpx.adobe.com/acrobat.html

Reader help: http://helpx.adobe.com/reader.html

Please note that full user guides for earlier versions of these programs are available from the Adobe Help pages by clicking on the link "Previous versions" under the "Help and tutorials" heading from the relevant link above. Commenting functionality is available from Adobe Reader 8.0 onwards and from Adobe Acrobat 7.0 onwards.

Firefox users: Firefox's inbuilt PDF Viewer is set to the default; please see the following for instructions on how to use this and download the PDF to your hard drive:

http://support.mozilla.org/en-US/kb/view-pdf-files-firefox-without-downloading-them\#w_using-apdf-reader-plugin 
OSEARCH ARTICLE

\title{
Spatial allocation of material flow analysis in residential developments: a case study of Kildare County, Ireland
}

Manoj Roy ${ }^{\mathrm{a} *}$, Robin Curry ${ }^{\mathrm{b}}$ and Geraint Ellis ${ }^{\mathrm{c}}$

${ }^{a}$ Lancaster Environment Centre, Lancaster University, Lancaster, UK; ${ }^{b}$ Institute for a Sustainable World, Queen's University Belfast, Belfast, UK; ${ }^{c}$ School of Planning Architecture and Civil

Engineering, Queens's University Belfast, Belfast, UK

\begin{abstract}
Studies of urban metabolism provide important insights for environmental management of cities, but are not widely used in planning practice due to a mismatch of data scale and coverage. This paper introduces the Spatial Allocation of Material Flow Analysis (SAMFA) model as a potential decision support tool aimed as a contribution to overcome some of these difficulties and describes its pilot use at the county level in the Republic of Ireland. The results suggest that SAMFA is capable of identifying hotspots of higher material and energy use to support targeted planning initiatives, while its ability to visualise different policy scenarios supports more effective multi-stakeholder engagement. The paper evaluates this pilot use and sets out how this model can act as an analytical platform for the industrial ecology-spatial planning nexus.
\end{abstract}

Keywords: Ireland; material flow analysis; spatial allocation; spatial planning; sustainable development

\section{Introduction}

While the policy-evidence relationship should never be viewed as being overly instrumental (Davoudi 2006), meeting the challenge of sustainable cities will mean that policy will have to be guided by specific criteria to ensure that development can respect the Earth's bio-physical limits (Kemp, Parto, and Gibson 2005). Spatial planning represents an important regulatory regime for promoting sustainability, being the key mechanism for ensuring development is most suitably located, protecting the most environmentally sensitive sites, encouraging construction at locations with lower environment sensitivity (such as brownfield sites) and by upholding the precautionary principle (Owens and Cowell 2011). Although the planning process has not always lived up to such aspirations, its role has been strengthened through the use of policy support tools capable of assessing the impact of development scenarios against normative ideas on sustainable development, not least in energy and resource use terms.

A particularly powerful concept for this has been urban metabolism (Wolman 1965), defined as "the sum total of the technical and socio-economic processes that occur in cities, resulting in growth, production of energy, and elimination of waste" (Kennedy, Cuddihy, and Engel-Yan 2007, 44). The concept emphasises that the environmental performance of urban areas is best understood not just in consumption terms, but in overall changes in the stock of material, i.e. the "material balance" (Eurostat 2001). Thus,

*Corresponding author. Email: m.roy1@lancaster.ac.uk 
the study of flow and accumulation of material (e.g. construction material, wastes, nutrients) is also a key to the effective environmental management of cities, and increasingly, a policy priority. To the OECD (2003), for example, efficient material flow chains are fundamental to sustainable development, having the potential to reduce the cumulative environmental impacts of a given system. Here "efficiency" refers to optimising the overall material utility, through use, reuse and recycling of available resources - all of these are intricately linked to our sociocultural behaviour (Zhang 2013). The efficiency of the material flow chain is not just a function of the manufacturing process, but of how consumers utilise goods. Indeed, changing consumer preferences can be a key driver of product innovation and efficient production, as well as of levels of product redundancy or recycle/reuse. Resource use is thus clearly a sociocultural phenomenon and is often subject to local, regional and national government regulations. As a result, there has been an increase in studies seeking to evaluate the complete metabolism of urban areas (e.g. Grimm et al. 2008, Barles 2009) or to model distinct elements, such as water (e.g. Baker 2009), construction material (e.g. Huang and Hsu 2003) or nitrogen (e.g. Færge, Magid, and Vries 2001). Chen and Chen (2012) have also attempted to model the carbon flow through an urban ecosystem, using Vienna as a case study, although acknowledge limitations arise from data availability across time series and between cities.

While these assessments of metabolism draw on the principles of material flow analysis (MFA), the majority has been undertaken by the industrial ecology community

Q2 with relatively little application in planning (Kennedy, Pincetl, and Bunje 2011). There are various reasons why such research has not been operationalised more by planning practitioners. Chrysolulakis et al. (2013), for example, blame the lack of knowledge exchange arising through poor communication between researchers and planners. However, a more fundamental reason may be that environmental analysis techniques like MFA draw on data available at fundamentally different units and geographic scale than those that are most useful to the planning process. Thus, while MFA typically involves comprehensive accounting of the material throughput of a defined societal sub-system (Haberl et al. 2013), spatial planning must address not only the broad goals of sustainability, but also work through a spatially specific framework that includes a wide range of actors and regulatory systems such as those governing property rights and economic development. Furthermore, it does this under conditions of uncertainty and feasibility (Yeo, Yoon, and Yee 2013).

For Sinclair et al. $(2005,70)$, the failure to integrate MFA into policy persists because “... no integrated model has been proposed that is capable of either mapping or predicting regional flows on a disaggregated basis. Nor does one exist that links these flows to regional and national economic accounting data." As such research on MFA and urban metabolism has not tended to inform planning policy and practice, apart from a number of key exceptions noted by Kennedy, Pincetl, and Bunje (2011), including attempts at developing sustainability indicators and major urban reconstruction. This situation means the two disciplines have progressed largely independently and leaving opportunities for cross-fertilisation rather neglected.

There have been a number of attempts to overcome these methodological difficulties. Examples include the use of a quasi-multi-regional input-output model and household expenditure data to allocate the consumption based carbon footprint (CF) of UK households based on the Local Area Resource Analysis (LARA) model (Druckman and Jackson 2009), and the Resource and Energy Analysis Programme (REAP) which has been used extensively in the UK to estimate material flows and carbon and ecological 
footprints (EF) (Wiedmann and Barrett 2005). However, while these approaches employ geo-demographic data, which allow allocation at any sub-national area level (including local authority (LA) area, or even postcode level if data were available), no attempt has been made to integrate the linkages with spatial modelling (ibid).

Given the paucity of research on the industrial ecology-spatial planning nexus, it is perhaps unsurprising that the development of a "construction ecology"; as a crucial element of a-sustainability (Kibert, Sendzimir, and Guy 2000) is still not effectively expressed through the spatial regulation of the built environment. Yet, the construction industry portrays particular characteristics of higher resource use, as many of its elements, e.g. buildings and other infrastructure, have a durability that extends well beyond a single generation, yet its use is often governed by socially defined needs and fashions (Srinivasan, O'Fallon, and Dearry 2003). Indeed, the useful lifecycle of buildings and their components can be unpredictable as different components wear out at differing rates and are often one-off items with limited opportunities for reuse (Kibert, Sendzimir, and Guy 2000). In particular, as the most important element of the built environment, housing takes the highest share of space, material and energy. For example, the UK based data show that the energy requirements for buildings exceed those for transport and industrial processes; the housing sector (including the consumption therein, for example, foods, paper, furniture, etc.) alone consumes almost $30 \%$ of total energy (Rylatt, Gadsden, and Lomas 2003), while in Ireland, this is $25 \%$ (O'Leary, Howley, and O'Gallachóir 2008). Contemporary studies on EF and CF have also highlighted the residential sector as a major contributor to environmental impacts - for example, a study from Northern Ireland estimated the share of housing of the total $\mathrm{EF}$ and $\mathrm{CF}$ to be as high as $39 \%$ and $48 \%$, respectively (Maguire, Curry, and McClenaghan 2008).

The longer lifecycle of built environment elements also raises two further conceptual issues. First, durable elements, in the form of the physical stock of service units (i.e. individual dwellings), function as points of continuous energy use. Second, the physical forms of buildings should be considered to be both a potential stock of material (for reuse and recycle) and a source of waste (by the end of their lifecycle). The proportion of material stock and waste in any one unit is subject to a range of factors, such as the method of construction and demolition $(C \& D)$, policies regulating material recovery and recycling and age of the unit.

In environmental terms, the more durable and energy efficient the existing residential units are, the more sustainable the system is, as this will reduce or delay demand for new facilities and associated expenditure of materials and energy. If existing units are energy efficient, they also require less operational energy $(\mathrm{OE})$. However, energy efficiency of units tends to be a function of space and time; generally, the older the unit, the less efficient it is, partly due to older, less efficient technology, and partly because it is being used, for a function for which it was not originally designed (US DoE 2008). It is also likely that units will become increasing relatively inefficient as new construction aligns with increasing building standards. Planned or enforced urban reconstruction may also result in large areas of demolition, and if this does not prioritise material recovery and recycling, replacement buildings will ultimately lead to more demand for raw material, and increased waste and emissions.

The impact, however, is not homogenous across the housing sector, with Ratti, Baker, and Steemers (2005) observing that energy consumption in buildings with similar functions can vary by a factor of 20 . This variability illustrates the potential of well focused interventions to reduce energy consumption in the housing sector, particularly 
considering that in a typical lifetime of 100 years, a residential building may consume between 80 and $100 \mathrm{GJ} / \mathrm{m}^{2}$ of energy (O'Leary, Howley, and O'Gallachóir 2008).

In addition to these quantifiable environmental impacts, from a political ecology perspective, the housing sector also consists of a number of dynamic, interconnected and mutually transformative physical and social processes (Swyngedouw 2006). As such, any environmental analysis of the housing sector cannot simply be viewed in techno-rational terms, but requires an understanding of the potential macroeconomic and microeconomic impacts and the complex sociopolitical factors involved (Broto, Allen, and Rapoport 2012). Furthermore, complexity arises when taking into account the temporal dimension, where differences between embodied and operational energies ${ }^{1}$ become particularly significant, and where a dwelling may evolve to meet the occupants' changing lifestyles, meaning that any assessment of the MFA of urban areas must be dynamic and consumer focused.

The incorporation of MFA into spatial planning policy and practice is, therefore, of more than merely academic interest - the ability to understand how to increase the efficiency of the flow of built environment materials is essential to ensure society's transition towards a more sustainable future. On the one hand, MFA and similar assessment tools can analyse aspects of society-environment interaction, by highlighting critical changes in patterns and processes in ecosystems related to these flows (Haberl et al. 2004). On the other hand, understanding the spatial distribution of consumption and other processes can support the development of community focused outcomes and strategies, whilst being mindful of unintended repercussions (Harris and Batty 1993). Therefore, a robust combination of MFA and spatial allocation has the potential to provide an analysis of the complex dynamics of society-environment interactions, and to model different scenarios for their effective governance.

This paper, therefore, presents an alternative approach to addressing this gap in knowledge, in an attempt to contribute to the development of a model for measuring flow of construction material at a spatial level which can then be used for developing spatial planning policies for urban development; the Spatial Allocation of Material Flow Analysis (SAMFA) model. This draws on concepts of urban metabolism and links these with an ability to visually represent the implications of spatially and temporally differentiated scenarios related to the accumulation of construction material flows and associated energy use in the housing sector in the specific context of Kildare County, Republic of Ireland. The rest of the paper discusses the framework and design of the model, evaluates its pilot application in Kildare and discusses its value, potential future development and wider application.

\section{The SAMFA model}

\subsection{Overall framing}

The SAMFA model has been structured into six modules - the three (M1-M3) of which define SAMFA, and the rest ensure SAMFA's wider application (Figure 1). The three interactive modules of SAMFA are located on the centre left of the figure. On its right and at the bottom of the figure are the most immediate users of, and contributors to, the model. Along the top are the application areas: input to policies and making other stakeholders aware of the learning that the model could encourage.

In fulfilling the objective of linking industrial ecology and spatial planning approaches, not only do the three modules that make SAMFA (i.e. M1-M3) 

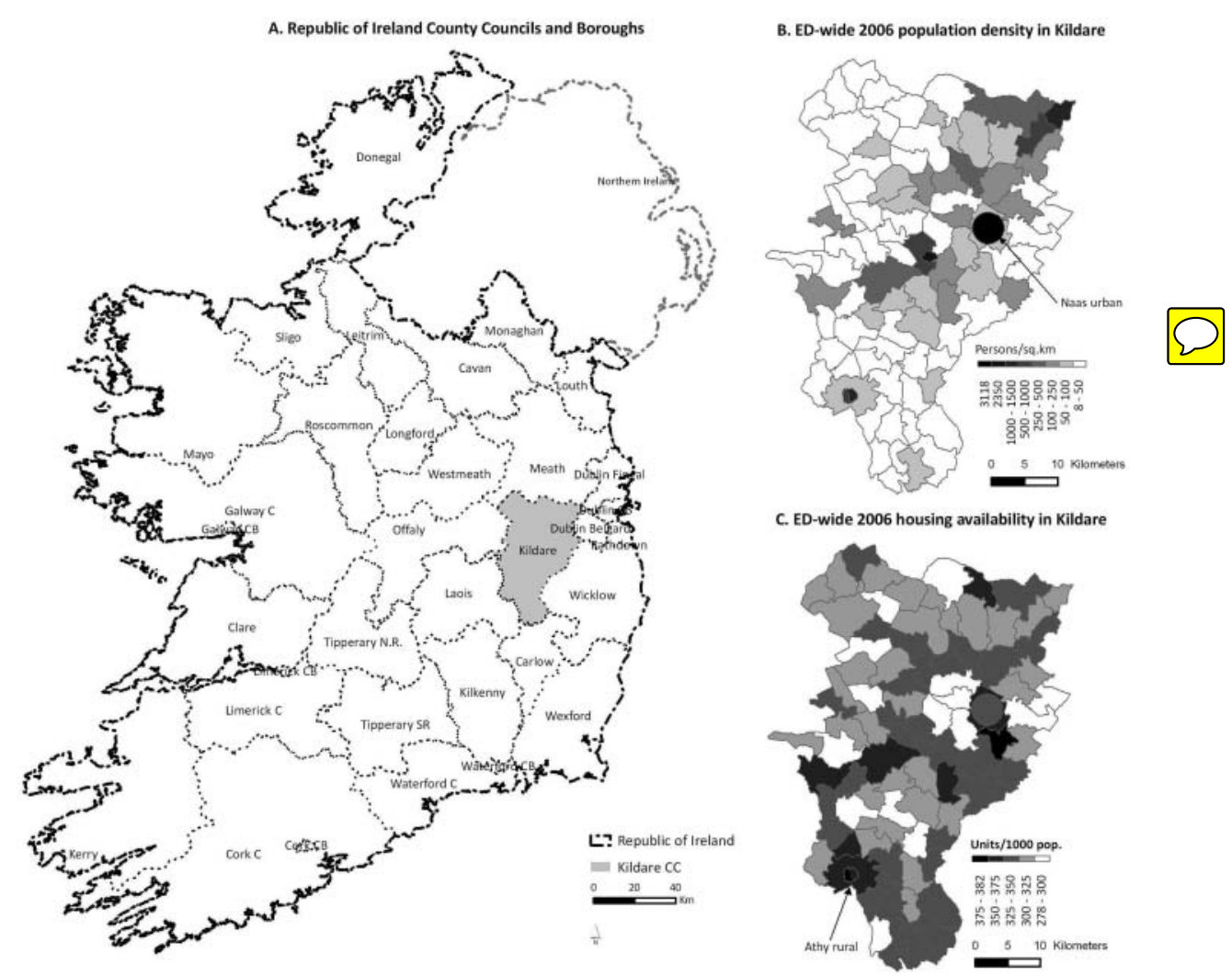

Figure 1. SAMFA framework.

incorporate well established industrial ecology concepts noted above - namely, consumer based, service unit and mass balance. They also adhere to key foundations of spatial planning, and successfully apply advanced spatial modelling techniques.

In terms of industrial ecology concepts, for example, both M1 and M2 are inspired by the consumer based and service unit concepts. This is evident in SAMFA's assumption that the actual use of construction material by the final consumers (i.e. households) begins only when a house is constructed, becomes occupied and then becomes added to the stock. Not until a unit is demolished or renovated does the question of recycling, reuse or waste of the construction materials arise. Thus, the main factors governing construction material flows in the housing sector, as modelled in M1 and M2, respectively, are in fact the demolition/renovation of old, and the construction of new, housing units. Based on these inflows and outflows, M3 then calculates the cumulative material balance at the base spatial unit, and ultimately, the aggregated material balance at the most relevant larger spatial unit.

In addition to being-industrial ecology relevant, the three SAMFA modules also explicitly incorporate spatial planning and modelling techniques. This is evident in the way SAMFA captures the spatial and temporal dynamics of the two aspects that drive construction material flows in housing sector: how new units are constructed, and how old units are demolished. Clearly, this is not just counting the number of units 
constructed or demolished, but by careful spatial construction of a number of social and planning variables through the following three steps:

- First, incorporation of a range of land and planning variables (Bramley 1993) with socio-demographic and technological factors to determine the spatial and temporal distribution of new housing units. This also includes estimating the availability of brownfield sites, which, in turn, may lead to more new units.

- Second, establishment of trends in material intensity ${ }^{2}$ and building life expectancy to determine the probability and spatial temporal pattern of demolition of old units (Schiller 2007; Müller 2005; Tanikawa et al. 2005). This has been combined with current material recovery, recycling and waste treatment practices, and any potential change in such practices, to quantify material outflows.

- Third, bottom-up spatial aggregation of the material balance resulting through this process of constructing new units and demolishing old units.

These types of spatial modelling are essentially a bottom-up approach which is in sharp contrast to the way MFA is assembled. This tension has been used to the advantage of SAMFA. For example, MFA is most reliable at the national level and its accuracy decreases as we disaggregate it to the local level. In contrast, the bottom-up approach is most robust at the local level, and its degree of relevance to planning decreases as we aggregate it to the higher levels. This implies that, at the spatially disaggregated levels, the results of the bottom-up approach can be treated as more useful than estimation based on the downscaling of the national level figures. A similar line of argument has been followed by Kytzia (2000).

Clearly, the ultimate level of disaggregation is the individual building unit, and it must be borne in mind that MFA cannot provide insights at this level. The coupling of MFA modelling with Life Cycle Analysis is one promising approach to allowdisaggregation to the level of a single unit or product (Goldstein et al. 2013), and additionally offers the possibility of addressing one of the most widely acknowledged weaknesses of the MFA approach, namely that every material flow is converted to the same unit (e.g. one tonne of PVC windows is treated the same as one tonne of stone), and that MFA merely quantifies the flows but does not by itself, offer a means of estimating the environmental impacts of the flows (Curry et al. 2011).

What is still unclear is the level at which the bottom-up results become less valid. In this context, Bannett and Newborough (2001) argue that the LA is the most effective level for energy auditing and emission estimation, and it is here that key regulatory decisions are made. A critical function of a model that can influence policies for the built environment is, therefore, an ability to allocate the material flow data to the LA level or below. As national level MFA data are being increasingly disaggregated at the level down to the LA level, this seems to be the level up to which the bottom-up results are aggregated. In addition to these spatial and analytical foundations, the model also needs to address its application context and be validated by members of its potential user community. Once again, in Anglo-Irish contexts, it is the LA level where important decisions are made.

Accordingly, in SAMFA, the electoral divisions (EDs) and county have been considered as the base unit (for spatially disaggregation analysis in M1 and M2) and spatial aggregation (for calculating aggregated mass balance in M3), respectively. Note that ED and County are Irish specific terms - the next section, therefore, provides a brief 
overview of these and other Irish spatial planning processes to position SAMFA in its specific application context.

\subsection{SAMFA application context}

The combination of MFA-spatial allocation in SAMFA was tested by taking just one element of the urban metabolism, construction material flows, examined in the context of a single county planning authority in the Republic of Ireland. Through this specific 260 application context, SAMFA has been able to locate within the national to county level policy hierarchy. Nationally, the MFA-spatial allocation is well grounded in Irish sustainable development policy, embedded within the national, sub-national and local level planning strategies and programmes. At the top of the policy hierarchy are the National Spatial Strategy (NSS), a long term policy with the current version running until 2020, and the National Development Plan produced every five years, currently 2012-2016. A range of regional level policies are created for the respective local and district authorities - the bottom level executive authority.

While the sustainability strategies on which these programmes and plans are founded can directly or indirectly benefit from studies on MFA (Roy, Ellis, and Curry 2010, Table 1.2), there has been no straightforward mechanism to bring the MFA-sustainability link into mainstream policy mechanisms in Ireland. In an effort to address these gaps in policy that the Irish Environmental Protection Agency (EPA) launched its Environmental Research, Technological Development and Innovation programme during 2000-2006, which funded an initial MFA project (Island Limits, 2004-SD-MS-22-M2) and following that, the development of the SAMFA model (2005-FS-34-M1).

Against this national level policy backdrop, the SAMFA model takes a bottom-up approach using data from one Irish local authority - County Kildare (Figure 2), selected based on six predefined criteria. ${ }^{3}$ Kildare lies to the immediate west and south-west of Dublin, the Irish capital, and in 2006 had a population of 186,000 people, in an area of $1692 \mathrm{~km}^{2}$ (a density of 109 persons $/ \mathrm{km}^{2}$ ) (CSO 2007). There are 89 EDs - the bottom level administrative units. Due to the proximity of Dublin, some parts of the county had experienced rapid urbanisation (e.g. ED Naas Urban with a population density of over 3100 persons $/ \mathrm{km}^{2}$ ), although other areas are still characterised by traditional rural housing patterns.

Kildare is regarded as part of the Dublin and the Mid-East regions, with most of the county categorised as part of the metropolitan hinterland. Its development activities are governed by a five year County Development Plan (CDP) prepared in-line with the NSS. In many respects, therefore, Kildare represents many features of the contemporary Irish built environment has been subject to some of the critical development processes experienced across the country and as such, provides a valuable laboratory for the testing of the SAMFA model. Note that while the current CDP is for 2011-2017 (Kildare CC 2011), for data consistency, this study incorporates CDP 2006-2011 (Kildare CC 2005). Indeed, except for some planning (e.g. countrywide development priority) and demographic (e.g. population projection) variables, values of other variables used in SAMFA model (see below) are not readily available for CDP 2011-2017. Nevertheless, as the core strategy for CDP 2011-2017 builds on the principles established in the previous CDP 2006-2011 (Kildare CC 2011), it can safely be assumed that the application of SAMFA model for 2017 (should all of the required data become available) will produce an equally valid result as for 2011 . 


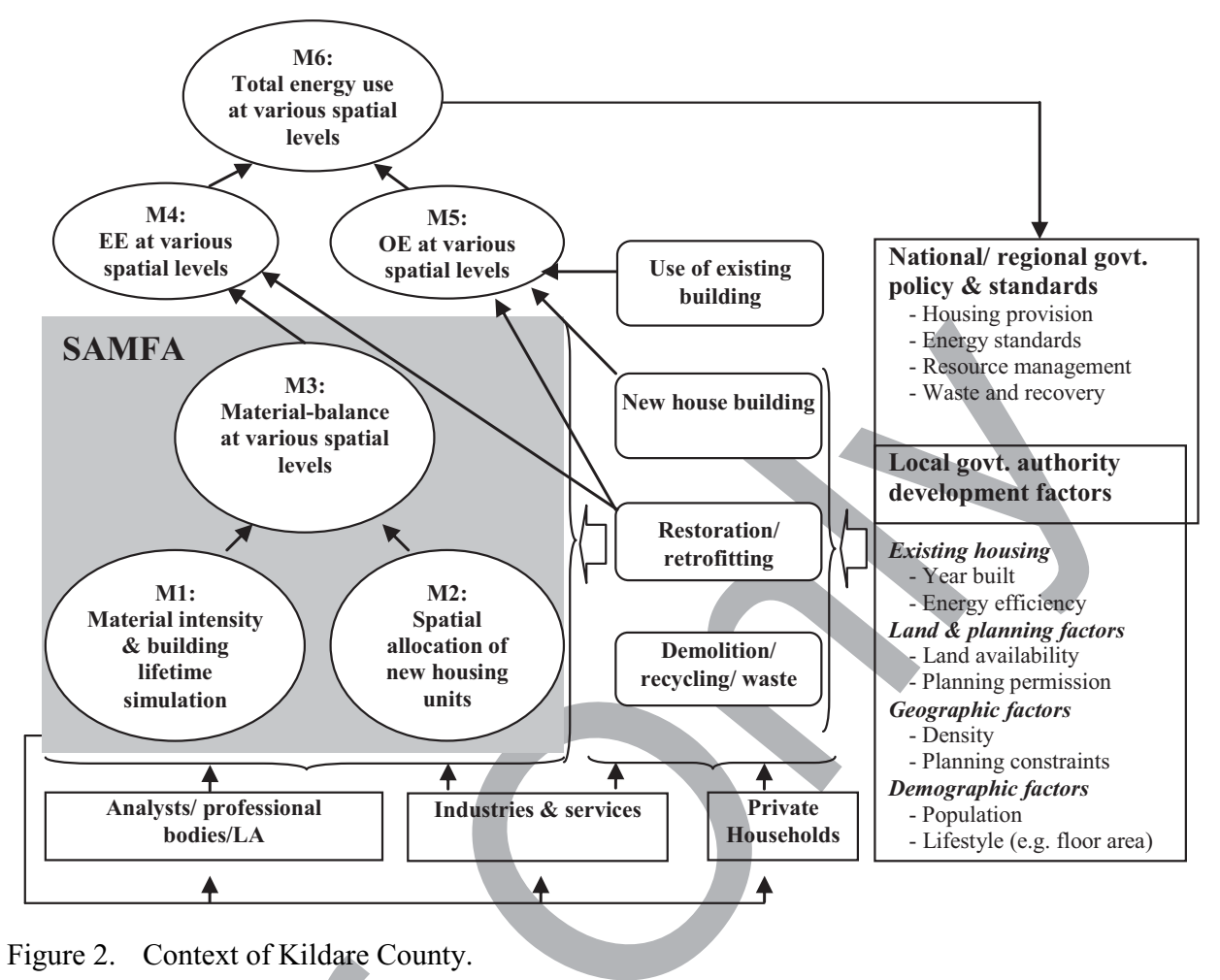

Figure 2. Context of Kildare County.

\subsection{Model design}

300 Building on the overall framing alongside a careful consideration of SAMFA's application context and data availability, the model base for individual modules has been determined as follows.

\subsubsection{Module 1 (M1): material intensity and building lifetime simulation}

The objective of M1 is to provide M2 and M3 with two pieces of key information: construction material intensity and probability of demolition at a given point in time. This is essentially a function of housing type, year built and spatial location. For this study, a simplified housing type (i.e. one_off house, terraced house and flat/apartment) and built year (in Irish census periods) were applied as a basis for the assumptions found in Tanikawa et al. (2005) and Schiller (2007).

To elaborate, Tanikawa et al. found that the construction material intensity of UK houses constructed during the past decade varied between traditional houses $\left(0.78\right.$ tonne $\left./ \mathrm{m}^{2}\right)$ and flats/apartments $\left(0.74\right.$ tonne $\left./ \mathrm{m}^{2}\right)$, while Schiller developed trend curves to model material intensity and room volume over time in German houses. We use these values alongside defining a trend curve, based on material flow analysis of housing stock, which allows the estimation of future demolition rates, using the average lifespan of different housing types. An empirical time series study of material intensity in the Irish housing sector was beyond the scope of this exercise.

The probability of demolition is derived at the ED level, using the housing building records of the Irish Central Statistics Office (CSO). Taking the statistics for 2001 and 
2006, it is possible to establish building life expectancy in Kildare, which varies between 38 and 65 years, with a standard deviation (SD) of 15-20 years. This is, however, based only on those buildings that have already been demolished, which is only $5.7 \%$ of the 2000 stock (CSO 2002, 2007). This, therefore, potentially understates the life expectancy of all buildings, and we find, for example, that $10 \%$ of the 2005 stock is still standing after 100 years and therefore not reflected in this data. This issue was overcome by following the approach of Müller (2005), where the following four types of information have been used to construct a distribution of life expectancy: minimum, maximum and average lifetime, and SD.

In SAMFA, we consider the average life expectancy found in the 2001 and 2006 statistics as the minimum life and assume the maximum life expectancy to be 120 years. The average of these two values is taken to be the average life expectancy of houses at the ED level, with the same SD calculated above. This enables us to calculate the probability of ED level housing demolition.

\subsubsection{Module 2 (M2): ED level allocation of new housing units}

The objective of module M2 is to provide module M3 with an ED wide fraction of the LA level housing supply by type. The LA wide housing supply is an external macro-level socio-economic indicator for SAMFA. We have defined four ED level spatial variables and three sub-variables to spatially allocate this exogenous housing supply for Kildare County. The variables and the corresponding data sources are as follows:

- Expected population. Trends in ED level population have been estimated using the Small Area Population Statistics. Using this and the Kildare CDP 2005-2011 targets, the ED wide expected population has been calculated.

- Land availability for development. This has three sub-variables: (1) supply of serviced land, as in the CDP 2005-2011; (2) brownfields available due to demolition of old houses; and (3) additional land suitable for development. Land area for item (3) has been calculated from ED areas, excluding the land areas of items (1) and (2), areas of nature conservation and existing built-up areas. Ideally item (3) should also exclude areas of flood risks; however, spatial data on flood risk levels in Ireland are currently unavailable. ${ }^{4}$

- Distance from Dublin. This is currently being-measured in aerial distance from the geometric centroid of Dublin County Borough to that of individual EDs. GIS data from OSI have been used for this purpose.

- County development factor. Based on the priority set in the CDP 2005-2011, we have defined an ordinal scale of $1-5$ in order of low to high priority for housing development.

In selecting these variables, we assume two principal regularities. First, following Bramley (1993), the allocation of new housing units to each ED is dependent on its relative advantage over all other EDs in terms of three planning factors: population, land availability for development and the development priority set by the planning authority. Second, inspired by the classic gravity based modelling technique (Putman and Chan 2001), distance to Dublin (the neighbouring, economic hub of Ireland) is an impedance to housing demand. In gravity based models, and therefore in SAMFA, such impedance is used as a negative exponential distribution defined by a parameter. 
A multiple regression is then developed, assigning a parameter for each variable noted above. The multiplication of variables enables the variables to influence each other in producing the dependent variable value. However, the variable land availability for development has been conceived as a cumulative expression of three sub-variables, with a corresponding parameter. The implication is that, while, for example, a change in ED level expected population or county development factor would certainly affect the number of housing units by type allocated to the corresponding ED. But changes in land availability will not have such an impact unless there is a change in three of its subvariables put together. This gives the final formulae as

$$
H_{i, j}^{(t)}(t)=H_{G i}^{(t)}(t) \times \frac{P_{j}^{\alpha_{i}}\left(t^{0}\right) \times e^{-D_{j}^{\beta_{i}}} \times\left(l_{s}^{\gamma_{i}^{\prime}}\left(t^{0}\right)+l_{b_{i}}^{\gamma_{i}^{\prime \prime}}\left(t^{0}\right)+l_{\text {aj }}^{\gamma_{i}^{\prime \prime \prime}}\left(t^{0}\right)\right) \times C_{j}^{\delta}(t)}{\left.\sum_{j} P_{j}^{\alpha_{i}}\left(t^{0}\right) \times e^{-D_{j}^{\beta_{i}}} \times\left(\sum_{j_{j}}^{t^{\prime \prime}}\right)+l_{\dot{j}}^{\gamma_{i}^{\prime \prime}}\left(t^{0}\right)+l_{\dot{j}}^{\gamma_{i}^{\prime \prime \prime}}\left(t^{0}\right)\right) \times C_{j}^{\delta}(t)}
$$

where $H_{i-i}^{(f)}$ is the number of housing unit by type $i$ allocated to $\operatorname{ED} j ; H_{C_{j}}^{(f)}$ number of total housing unit by type $i$ located in Kildare County; $P_{j}$ population in ED $j ; D_{j}$ distance from Dublin to $\mathrm{ED} j ; l_{s}$ serviced land in $\mathrm{ED} j ; l_{t}$ brownfield in ED $j ; l_{\pi}$ additional land suitable for development in $\mathrm{ED} j ; C_{j}$ determinant of planning factor in $\operatorname{ED} j$ and $\alpha, \beta, \lambda^{\prime}, \lambda^{t \prime}, \lambda^{t+1}$ and $\delta$ parameters to calibrate.

\subsubsection{Module 3 (M3): material balance at different spatial scales}

The outcome of modules M1 and M2 now become inputs for module M3, helping to compute the total material input. For example, the material intensity of a housing type at a given point in time (from M1) is multiplied with the total newly constructed floor space of that particular building type in individual ED (from M2) to calculate the corresponding material input as

$$
M_{j}^{(t)}(t)=\sum_{i} H_{i, j}^{(t)}(t) \times m_{i}(t)
$$

where $M_{j}^{\left(\mathrm{f}_{)}\right.}$is the material inflow in $\mathrm{ED} j ; H_{i j}^{(t)}$ is the supply of housing unit of type $i$ in ED $j$ and $m_{i}$ is the material stock in individual housing type $i$, which is equivalent to material intensity multiplied by floor space index.

Module M3 also calculates material outflow using the ED level housing demolition and existing standards of recovery and reuse of $C \& D$ waste. Data on waste management have been obtained from the national waste report of the EPA (Collins, Bolloch, and Meaney 2005), which show that around $90 \%$ of C\&D waste is currently recycled in Ireland. This does not indicate whether a proportion of the collected waste is reused in the house building industry, as studies such as Schiller (2007) observe that recovered C\&D waste is mostly used in sectors other than residential, such as road construction. However, it is assumed that there will be some reuse of demolition waste, particularly in redevelopment schemes and in the case of older buildings, whose fixtures may be of value to the architectural salvage sector. Such a provision has been made in the construction of the integrated scenario (see Section 2.5). But in the baseline scenario, a $0 \%$ recycling rate has been assumed, to reflect widely acknowledged anomalies in the data for C\&D waste collection and recycling rates in Ireland. Indeed, this issue has been specifically highlighted in the 2011 Irish National Waste Report, noting significant 
discrepancies between the reported quantities of $C \& D$ waste collected and recovered (EPA 2011). This gives us the following two final equations:

$$
\begin{gathered}
M_{j}^{(\theta)}(t)=\sum_{\underbrace{i, j}}^{(\theta)}(t) \times m_{i}\left(t^{\prime}\right) \\
W_{j}^{(\theta)}(t)=M_{j}^{(\theta)}(t) \times\left(1-r^{(\underline{D})}(t)\right)
\end{gathered}
$$

where $M_{j}^{(\theta)}$ is the material output from $\operatorname{ED} j ; H_{i j}^{(\theta)}$ is the demolition of housing unit type $i$ in $\mathrm{ED} j ; m_{i}$ above; $W_{j}^{(\theta)}$ is the waste in $\mathrm{ED} j$ and $r_{(B)}$ is the material recovery factor during demolition of housing.

Based on the estimated housing stock by type and the corresponding floor space index, modules M4 and M5, respectively, estimate the embodied energy (EE) and OE use, and M6 the total energy use. Data on floor space index come (for 2005), and extrapolated (for 2011) from Irish housing statistics (DoEHLG, 2007). Note that EE can be both initial and recurred - the former through new construction and the latter through periodic renovations or extensions. The amount of initial EE is calculated from the total new housing units by type, estimated in M2. No Irish specific data are available for this; although a study by the Environmental Change Institute (Palmer et al. 2006) notes that this can vary from 0.25 (sustainable homes - low estimate) to $0.8 \mathrm{MWh} / \mathrm{m}^{2}$ (traditional homes - high estimate). In this study, a similar range has been assumed. With regard to recurrent EE, two studies have been consulted - one shows that in Dublin the average renovation frequency is once in 20 years. ${ }^{5}$ The other (Yohanis and Nortonne 2002) shows that the recurrent EE increases exponentially and periodically $-0.7 \mathrm{MWh} / \mathrm{m}^{2}$ after the first 25 years, $1.73 \mathrm{MWh} / \mathrm{m}^{2}$ after the second 25 year period and $4 \mathrm{MWh} / \mathrm{m}^{2}$ after the fourth 25 year period. Accordingly, the values observed in the second study have been used for Kildare, but at 20 year intervals. Finally, the calculation of OE has been based on O'Leary, Howley and O'Gallachóir (2008), who show that in 2005 the average Irish household used a total of 8.3 MWh (1.8 MWh from electricity and 6.5 MWh from fuel). The data also show a slightly rising trend, which has been used to estimate the OE data in 2011 scenarios. Note that these are national average, and not disaggregated at the ED/ country level.

\subsection{Calibration and validation}

The SAMFA model has been subject to three types of analysis for calibration and validation. First, a goodness of fit analysis, the objective of which is to identify the set of parameter values that maximises the goodness of fit $\left(R^{2}\right)$ between ED wide observed and estimated supply of housing units by type in 2006. Data for 2005 (i.e. $t^{0}$ ) and 2006 (i.e. $t$ ) have been compiled from a variety of sources. A high correlation (over $90 \%$ ) between observed and estimated housing units has been obtained (Table 1). This suggests that the parameters would offer a reasonably accurate prediction of ED level housing units.

Second, an inter-parameter analysis, following Elshkaki et al. (2005), to determine what combinations of parameters produce the best goodness of fit. This analysis reveals that a combination of all parameters produces the best prediction. Finally, the examination and validation of the SAMFA model, and the pilot results derived from it, by local stakeholders and expert groups. Examination by the local stakeholders included meetings with Kildare County Council and the EPA. Validation by the expert communities involved peer review in the form of an expert group meeting hosted by 
Table 1. Parameter calibration.

\begin{tabular}{|c|c|c|c|c|c|c|}
\hline \multirow[b]{2}{*}{ Parameter } & \multicolumn{2}{|c|}{ One-off house } & \multicolumn{2}{|c|}{ Terrace house } & \multicolumn{2}{|l|}{ Flat } \\
\hline & Calibrated value & $R^{2}$ & Calibrated value & $R^{2}$ & Calibrated value & $R^{2}$ \\
\hline$\alpha$ & 1.025 & 0.9231 & 1.035 & 0.9114 & 1.05 & 0.9228 \\
\hline$\beta$ & -0.001 & & -0.001 & & -0.001 & \\
\hline$\gamma^{\prime}$ & 0.4 & & 0.4 & & 0.4 & \\
\hline$\gamma^{\prime \prime}$ & 0.9 & & 0.92 & & 0.925 & \\
\hline$\gamma^{\prime \prime \prime}$ & 0.375 & & 0.375 & & 0.375 & \\
\hline$\delta$ & 0.005 & & -0.13 & & -0.126 & \\
\hline
\end{tabular}

Centre for Urban and Regional Ecology, University of Manchester (see Roy, Ellis, and Curry 2010 for further details).

\subsection{SAMFA application}

The SAMFA model has been applied in two ways: (1) to estimate and spatially allocate construction material flows and associated total energy use at the ED level and LA level in Kildare County, using mostly observed values for the concerned variables; and (2) to construct two alternative scenarios for a future year using mostly predicted/assumed values for those variables. The former has been conducted for the year 2005, the latest year for which the maximum amount of observed data was available. In the latter, a baseline and an integrated scenario have been constructed for 2011 (see Section 2.2 for a justification for choosing 2011 in which to construct the scenarios). As the names indicate and Table 2 shows, the baseline scenario replicates conditions that best describe the current trend, while the integrated scenario incorporates a range of potential material efficiency and energy saving policy options.

In terms of estimation and spatial allocation of material balance, the following quantity of construction material flows occurred in 2005: inflow 813,000 tonnes, outflow 404,000 tonnes, a net addition to stock of 409,000 tonnes. As expected, ED Naas Urban shows the highest quantity of net addition to stock, followed by two other urban EDs Celbridge and Maynooth (Figure 3). A number of rural EDs show a negative net addition to stock, meaning that in these EDs the outflow is more than inflows. In these EDs, there is a higher proportion of old housing units, with a comparatively low number of new housing units constructed in 2005.

The 2011 scenarios (baseline as well as integrated) also reveal significant ED wide variations in terms of net addition to stock, and that in some EDs there is net material gain, while in others a net deficit. However, in terms of cumulative material balance at the county level, the scenarios show a considerable reduction in material inflows, outflows and net addition to stock compared to 2005. These figures for the two scenarios in 2011 are baseline (inflow: 652,000 tonnes; outflow: 413,000 tonnes and net addition: 239,000 tonnes) and integrated (inflow: 601,000 tonnes; outflow: 381,000 tonnes and net addition: 220,000 tonnes). Interestingly, not until the net addition to stock of urban EDs are added do both scenarios show reduction in cumulative net addition to stock compared

Q10 to 2005 (Figure 4). The figure also reveals a similar picture when the cumulative net addition to stock in the integrated scenario is compared with that in the baseline scenario.

There may be a number of reasons for this, but two key ones are that both material intensity and floor space index values are lower in 2011 than 2005, and that a 
Table 2. Scenario construction.

\begin{tabular}{|c|c|c|c|}
\hline \multirow[b]{2}{*}{ Module } & \multirow[b]{2}{*}{ Variable type (unit) } & \multicolumn{2}{|c|}{ Assumptions ${ }^{i}$ for variable and parameter values } \\
\hline & & Baseline & Integrated \\
\hline \multirow[t]{4}{*}{ M1 } & $\begin{array}{l}\text { (a) Material intensity } \\
\text { (tonne } / \mathrm{m}^{2} \text { ) }\end{array}$ & (a) Based on existing trend & $\begin{array}{l}\text { (a) } 80 \% \text { of new units to follow } \\
\text { existing trend; the rest to have } \\
10 \% \text { lower intensity than } \\
\text { existing trend }\end{array}$ \\
\hline & $\begin{array}{l}\text { (b) Maximum life } \\
\text { expectancy (years) }\end{array}$ & (b) 120 & (b) $120^{\mathrm{iii}}$ \\
\hline & $\begin{array}{l}\text { (c) Demolition probability } \\
(\%)\end{array}$ & (c) Based on existi & $\begin{array}{l}\text { (c) Based on existing trend but } \\
\text { with a minimum lifetime }\end{array}$ \\
\hline & $\begin{array}{l}\text { (d) Renovation frequency } \\
\text { (years) }\end{array}$ & (d) 20 & \\
\hline \multirow[t]{4}{*}{ M2 } & (a) Expected population & $\begin{array}{l}\text { Variable (existing trend) } \\
\text { parameter (as calibrated) }\end{array}$ & $\begin{array}{l}\text { (a) Variable (existing trend); } \\
\text { parameter (as calibrated) }\end{array}$ \\
\hline & $\begin{array}{l}\text { (b) Three sub-variables } \\
\text { of land availability } \\
\text { (hectare) }\end{array}$ & (b) Same as (a) & $\begin{array}{l}\text { (b) Same as (a), except that the } \\
\text { parameter for sub-variable } \\
\text { brownfield land has been } \\
\text { doubled }^{\text {vii }}\end{array}$ \\
\hline & $\begin{array}{l}\text { (є) Negative exp. of } \\
\text { aerial distance } \\
\text { from Dublin }(\mathrm{km})\end{array}$ & (c) Same as (a) & (c) Same as (a) $)^{\text {viii }}$ \\
\hline & $\begin{array}{l}\text { (d) Planning factor } \\
\text { (ordinal scale } 1-\end{array}$ & (d) Same as (a) & $\begin{array}{l}\text { (d) Same as (a), but the parameter } \\
\text { value has been doubled }\end{array}$ \\
\hline M3 & Material reus & $0 \%$ & $20 \%{ }^{x}$ \\
\hline \multirow[t]{2}{*}{ M4 } & (a) Initial EE & $\begin{array}{l}\text { (a) } 0.8 \text { (traditional homes - } \\
\text { high estimates) }\end{array}$ & $\begin{array}{l}\text { (a) } 0.8 \text { for } 80 \% \text { new units, and } \\
0.25 \text { for the rest } 20 \% \\
\text { (Sustainable homes - } \\
\text { low estimate) }\end{array}$ \\
\hline & $\begin{array}{l}\text { (b) Recurrent E } \\
\left(\mathrm{MWh} / \mathrm{m}^{2}\right)\end{array}$ & $\begin{array}{l}\text { (b) Existing trend, at } \\
20 \text { year interval }\end{array}$ & $\begin{array}{l}\text { (b) Existing trend, but at } 25 \text { year } \\
\text { interval }^{\text {xii }}\end{array}$ \\
\hline M5 & $\mathrm{OE}\left(\mathrm{MWh} / \mathrm{m}^{2}\right)$ & $\begin{array}{l}\text { Existing trend including } \\
\text { current level of rise }\end{array}$ & $\begin{array}{l}\text { Existing trend, but no } \\
\text { further rise } \\
\text { xiii }\end{array}$ \\
\hline 16 & & $\mathrm{n} / \mathrm{a}$ & $\mathrm{n} / \mathrm{a}$ \\
\hline
\end{tabular}

\section{Notes and justification:}

${ }^{\mathrm{i}}$ For existing trend and calibrated values, see Section 4.2 and Table 1, respectively.

ii Irish Friends of the Earth (FoE 2006) advocates extension of "Greener Homes" grants and tightening of

building regulations for new houses; so reduction in material intensity is likely.

iiii There is no current policy on this issue, as such current trend has been proposed.

${ }^{\text {iv }}$ Following FoE (2006), it is likely that existing housing units will be used for longer than now.

${ }^{\mathrm{v}}$ Source: Yohanis and Norton (2002).

${ }^{\mathrm{vi}}$ This follows Kildare CDP 2005-2011 which is based on existing population trend.

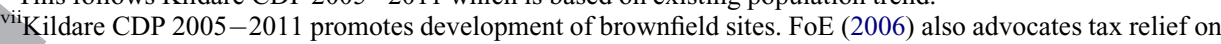
brownfield sites. These will expedite brownfield land development.

viii There is no policy/study to support otherwise.

${ }^{\mathrm{ix}}$ Implementation of CDP 2005-2011 is a top priority for Kildare CC.

${ }^{\mathrm{x}} \mathrm{EPA}$ emphasises incremental waste reuse (Bolloch et al. 2007).

${ }^{\mathrm{xi}}$ Ireland has set a target of making 40\% of new homes energy efficient by 2012 (FoE, 2006).

xii Source: Yohanis and Norton (2002).

${ }^{x i i i}$ Recent trend shows a sign of flattening out (O’Leary, Howley, and O'Gallachóir 2008). 

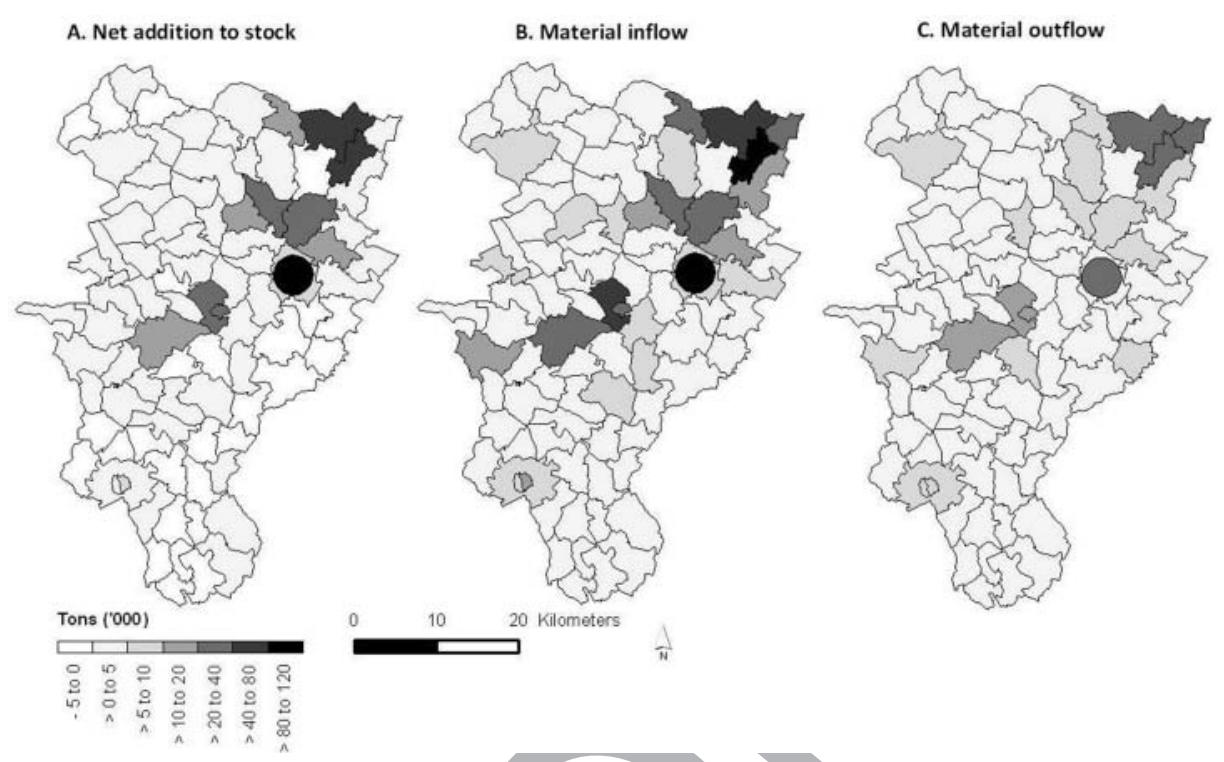

Figure 3. Spatial allocation of construction material flows in 2005.

significantly higher number of new housing units were built in urban than rural EDs during 2005-2011. Moreover, the values for all of the two measurement factors (material intensity and floor space index) in the integrated scenario-are less than in baseline, although the quantity of new housing units is same for the two scenarios. This is explained by the fact that the integrated scenario promotes more energy efficient and material efficient new dwellings (Table 2). A direct consequence of this is a significant reduction of material flows in urban EDs. Indeed, the reduction in urban EDs is so great that this counterbalances the higher material accumulation in rural EDs to produce an overall county level reduction in integrated scenario than both baseline and 2005.

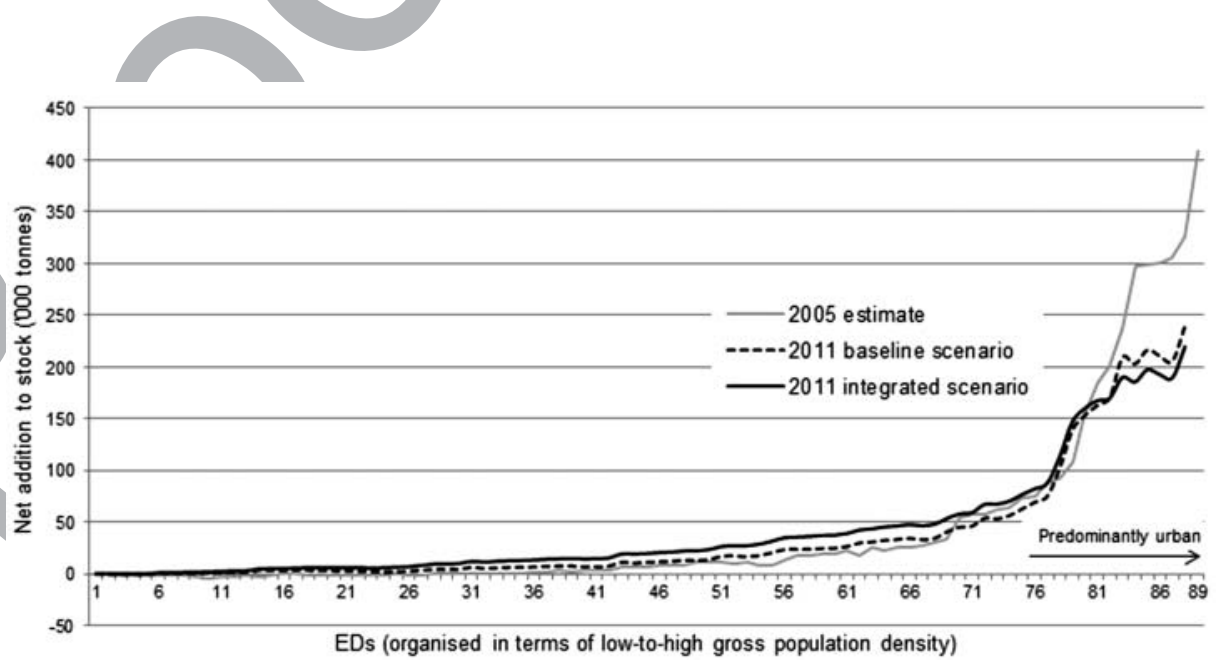

Figure 4. Cumulative net addition to stock in 2005 and under the two scenarios for 2011. 


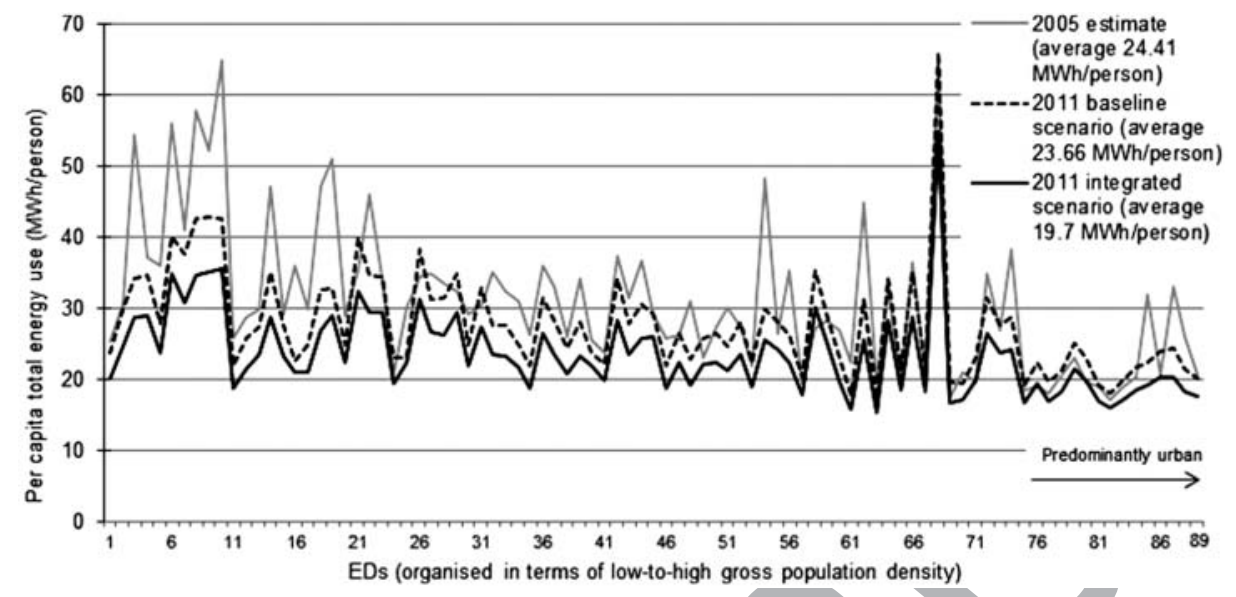

Figure 5. Per capital total energy use in 2005 and under the two scenarios for 2011.

A more dramatic and, perhaps, desirable picture emerges when energy use scenarios are constructed and compared. The per capita energy use levels in the integrated scenario are much lower than those of the baseline scenario and in 2005 (Figure 5). Indeed, the SAMFA pilot study suggests the average total energy use in Kildare in 2011 could be between 23.66 (baseline scenario) and 19.7 MWh/cap (integrated scenario), compared to $24.41 \mathrm{MWh} /$ cap in 2005.

As with the material flows, there is a significant ED wide variation in the total energy use for both scenarios. But unlike material flows, the per capital total energy use in both scenarios is consistently lower than 2005 for rural as well as urban EDs. Another significant observation that Figure 5 reveals is per capital total energy use is much lower in urban than rural EDs. There are many reasons for this, such as the age profile and density of the existing housing stock, and the likelihood and type of new construction. For example, ED Athy Rural has a lower population density (thus lower building density i.e. number of housing units per unit land area) but a higher housing availability. Most of its housing stock is relatively old, with a relatively large floor area; as a result, the ED appears to be using the highest amount of energy under both scenarios (Figure 5). Unfortunately, current planning policies are unaware of this fact, so the ED was not awarded a higher ordinal value for policy factor in the integrated scenario.

The above spatial differences notwithstanding, the integrated scenario offers a substantial reduction in total energy use, with an average person using about $17 \%$ less total energy compared to the baseline scenario. The integrated scenario is, therefore, a "clear winner" here, thus offering a viable strategy for meeting national emission targets. However, such a conclusion is rather tentative as one must acknowledge the difficulties in securing effective implementation of the integrated scenario, whilst recognising the assumptions underlying the data as explained above.

\section{Discussion}

The pilot application of SAMFA provides insights and information on the sustainability of the Irish built environment in at least two ways. First, it highlights the influence of urban form and building design on reducing building energy use. Second, it suggests that 
not only can the formulation and implementation of spatial planning guidelines greatly improve both material and energy efficiency, but that spatial planners can also use spatial visualisation of material/energy use hotspots as evidence to identify "problem" areas.

In terms of the urban form and building design, while it is widely accepted that higher densities can lead to reduced energy costs due to influences on travel patterns and modes (e.g. Banister, Watson, and Wood 1997), the influence on other aspects, particularly EE, is less well established. In this regard, SAMFA confirms that there is a negative correlation between population/building density and material use and thus, energy consumption. The higher the population/building density, the lower the material demand Q11 and EE use become.

SAMFA also suggests that while the planning guidelines in Ireland (and indeed in most developed nations) promote higher density developments, this has been poorly implemented or is only influencing the form of the built environment incrementally and at a very slow pace. In Ireland, for example, guidelines for residential development recommends planning authorities to "review and vary, if necessary, their Development Plans to promote higher residential densities" (RoI 2003, 7). Yet, there is much evidence that suggests the preference of rural living and the cost of houses in urban areas have resulted in urban sprawl and long distance commuting (e.g. Hoggart 2003). This is translated into a contrasting outcome in terms of residential densities between urban and rural areas. In urban areas, the average number of units per hectare has steadily increased from about 25 in 2000 to 31 in 2005, but the average size of units has remained static at about $78 \mathrm{~m}^{2} /$ unit. In contrast, in rural areas, the size of units is growing (from $144 \mathrm{~m}^{2} /$ unit in 2002 to $149 \mathrm{~m}^{2} /$ unit in 2005) despite a falling household size (from 3.34 in 1991 to 2.81 in 2006).

Thus, it appears that the sustainability gains resulting from positive trends in the regulatory standards of urban development (i.e. increased densities, improved building standards) have been negated in excessive consumption in ruralfront in Ireland. There is, therefore, a major issue in both the implementation of current planning guidelines and the developing policy to supply land for rural based and urban based housing development. This issue has been specifically highlighted in SAMFA through the development of alternative scenarios. The pilot run shows that there can be substantial sustainability gains in urban areas, such as ED Naas Urban. However, in rural areas, such as ED Athy Rural, a high energy use continues to remain as a major concern despite showing a reduction in material flows. In countries such as Ireland, where the preference for rural living is deeply rooted with the country's history and where the rural lobby is strong, while the planning restraint is relatively weak, tackling energy consumption in rural areas becomes the major issue facing the development of the built environment. It is, however, noteworthy that the integrated scenario developed through SAMFA shows a particular impact on the OE use even within rural areas.

These findings can vastly enhance LAs' capacity to develop alternative energy consumption and emission scenarios that could provide a basis for local development planning, which in turn may underpin the formulation of more informed and coherent regional/national plans. Moreover, the scenario based structure of SAMFA makes it an ideal candidate to be implemented as a valuable planning support system (Geertman and Stillwell 2003). Such a system is capable of helping decision-makers and stakeholders conceptualise the wider consequences of both the settlement structures projected in the development plan system and the consequences of poor implementation of adopted policy. It is suggested that this could also be further integrated into more sophisticated sustainability appraisal tools for undertaking a strategic environmental assessment (SEA) 
of any policy with a significant spatial outcome, as required by EU Directive 2001/42/EC. The need for material flow analysis to facilitate such integration is also widely acknowledged by leading industrial ecology scholars, notably Fischer-Kowalski et al. (2011).

Indeed, the experience of developing SAMFA with the benefit of interaction between the disciplines of industrial ecology and spatial planning helps us to suggest that the tool is well placed to contribute to the further development of evidence based policy in this field. This then helps overcome some of the institutional and professional barriers to the development of a more holistic approach to sustainability planning in the UK and Ireland (Roy and Ellis 2010). Thus, SAMFA has the potential to be adapted to a variety of settings, but will need to be institutionalised involving a range of stakeholders, including professionals/organisations such as architects, spatial planners, transport planners, waste managers and utility companies; and stakeholders such as members of strategic policy committees, county and city development boards, environmental interests; and LA community representatives. To address data related issues, participation from the following organisations has also to be sought: CSO; Ordinance Survey Ireland; EPA; Department of the Environment, Community and Local Government; Department of Communications, Energy and Natural Resources; and Construction Industry Federation.

In terms of the implications for moving to a more sustainable regulation of the built environment, SAMFA, therefore, provides insights for a more evidence based approach to policy-making. However, the value of the model lies not just in these terms, but in its potential wider contributions. The model framework as well as its application offers high level pedagogical value to a range of stakeholders including politicians, planners, professional bodies, industries and members of the public because of its abilities to produce visual representations of sustainability scenarios that increase the understanding of those involved in decision-making.

\section{Conclusion}

The development of the SAMFA model is based on a number of premises that (1) the built environment is a priority for progress towards a sustainable future; (2) a critical arena for decision-making in this field lies at the LA level and (3) spatial allocation of MFA generates evidence base about the environmental consequences of existing and future development patterns on which more progressive policy can be developed. The model has been found on recent developments in the field of industrial ecology, in particular mechanisms to translate national trade accounts into material flows with the capability of illustrating national imperatives for resource planning.

However, while effective global agreements and national strategies are essential elements of governance for sustainable development, it is at the local level where the majority of required actions take place (Gilbert et al. 1996); hence the enduring sagacity of the phrase "thinking globally - acting locally". Thus, while national material flow accounts have some conceptual value, it is the ability to translate this to understanding the metabolism of settlements at the local level that will bring major breakthroughs. The SAMFA model has attempted to do this using the concept of spatial allocation of the national material flows, based on an understanding of not just industrial ecology, but also spatial modelling and the policy needs of local planning authorities.

The SAMFA model has attempted to do this using a bottom-up approach based on numbers of housing units within an administrative unit. One limitation of the model is that it does not yet include the material flows associated with the infrastructure (roads, 
bridges, etc.) required to support residential buildings. Research by Schiller $(2007,2)$ has shown that in some scenarios "material flows for neighbourhood roads and supply infrastructure can be much greater than material flows for building". We have made specific recommendation with respect to this issue below.

It is suggested that SAMFA begins to map out a future direction for a meta-discipline of sustainability planning. This requires further development of SAMFA in terms of its accuracy, through undertaking a few critical analyses as follows:

- Conducting a sensitivity analysis, to rule out where uncertainties in data influence the most.

- Testing the model across scales, such as for different LA areas, to determine how the model parameters are sensitive to scale and contexts.

- Validating SAMFA predictions against actual data (e.g. for 2011). Actual data unavailable in official statistics should be gathered via field survey and/or through image processing.

- Collecting and applying better quality data, for example, by validating the assumed built environment data (e.g. actual life expectancy of buildings through field surveys) and by incorporating data from each of the Irish county councils and boroughs to provide a complete spatial model of the national material flow for construction materials.

- Inclusion of sectorial material flow data allocated "top-down" from the national accounts, to allow integration of material flows related to supply infrastructure to be modelled. Once complete, this will then provide a valuable predicting and monitoring tool capable of integrating national and local spatial planning objectives with actual environmental impacts.

Should these wider developments to the model prove to be similarly successful, there is then the potential to transfer the modelling approach to other areas of the built environment, for example, commercial development and other key contributors of greenhouse emissions. Ultimately, it is intended to develop a meta-model that includes a range of other economic sectors, so that those patterns of consumption that can have important environmental impacts can be allocated to a local scale. At this stage, we believe that the most useful area of research for the future development of spatial allocation of material and energy flow analysis is the exploration of the opportunities for integration of bottom-up modelling, with national MFA accounts.

We hope that this research can provide insights for other researchers and help set out the priorities for research to support this important policy area.

\section{Acknowledgements}

This paper originates from a postdoctoral research funded by the Irish EPA (Ref. 2005-FS-34-M1). We are particularly thankful to Kildare County Council for participating in the study. We also gratefully acknowledge helpful and constructive comments from several expert level participants.

\section{Notes}

1. Embodied energy (EE) is defined here as being the sum of the energy requirements associated, directly or indirectly, with the construction of the housing unit. Operational energy (OE) is defined here as being the energy is-that used in heating, cooling, cooking, etc. during the occupation and the use of the housing unit. 
2. Material intensity is defined here as in tonnes of construction material per square metre of floor space.

3. These are (a) area; (b) development potential; (c) proximity to the border; (d) convenience for the research team; (e) presence of GIS data and (f) willingness to participate in the study.

4. The Office of Public Works is currently undertaking the Flood Hazard Mapping programme; the results were unavailable during the analysis (seehttp://www.floodmaps.ie/AboutTheSite. htm, accessed 15 March 2010).

5. Seehttp://www.bsrec.bg/newbsrec/rosh/data/products/analysis/marketanalysis_dublin.pdf (Accessed 15 March 2010)

\section{References}

Ayres, R.U. 2004. "On the Lifecycle Metaphor: Where Ecology and Economics Diverge." Ecological Economics $48(4): 425=438$.

Baker, L.A. 2009. The Water Environment of Cities. New York: Springer.

Banister, D., S. Watson, and C. Wood. 1997. "Sustainable Cities: Transport, Energy, and Urban Form". Environment and Planning B 24 (1): 125-144.

Bannett, M., and M. Newborough. 2001. "Auditing Energy Use in Cities." Energy Policy 29: $125-134$.

Barles, S. 2009. "Urban Metabolism of Paris and Its Region." Journal of Industrial Ecology 13 (6): $898-913$.

Bolloch, O.L., J. Cope, B. Meaney, and I. Kurz. 2007. National Waste Report 2006. Wexford: Environmental Protection Agency, Johnstown Castle Estate.

Bramley, G. 1993. "The Impact of Land Use Planning and Tax Subsidies on the Supply and Price of Housing in Britain." Urban Studies 30: 5-30.

Broto, V.C., A. Allen, and E. Rapoport. 2012. "Interdisciplinary Perspectives on Urban Metabolism." Journal of Industrial Ecology 16 (6): 851-861.

Collins, C., O.L. Bolloch, and B. Meaney. 2005. National Waste Report 2004. Wexford: Environment Protection Agency (EPA).

Chen, S., and B. Chen (2012). Network Environ Perspective for Urban Metabolism and Carbon Emissions: A Case Study of Vienna, Austria. Environmental Science \& Technology 46 (8): 4498-4506.

Chrysolulakis, N., M. Lopes, R. San José, C.S.B. Grimmond, M.B. Jones, V. Magliulo, J.E.M. Klostermann, A. Synnefa, Z. Mitraka, E.A. Castro, A. González, R. Vogt, T. Vesala, D. Spano, G. Pigeon, P.F. Smith, T. Staszewski, N. Hodhes, G. Mills, and C. Cartalis. 2013. "Sustainable Urban Metabolism as a Link Between Bio-physical Sciences and Urban Planning: The BRIDGE Project." Landscape and Urban Planning 112: 100-117.

CSO (Central Statistics Office). 2002. Census 2001. Dublin: The Stationary Office.

695 CSO (Central Statistics Office). 2007. Census 2006. Report. Volume 6 - Housing. Dublin: The Stationery Office.

Curry, R, C. Maguire, C. Simmons, and K. Lewis. 2011. "The Use of Material Flow Analysis and the Ecological Footprint in Regional Policy Making: Application and Insights from Northern Ireland." Local Environment 16 (2): 165-179.

700 Davoudi, S. 2006. "Evidence-Based Planning: Rhetoric and Reality." DisP 165 (2): 14-24.

DoEHLG (Department of the Environment, Heritage and Local Government). 2007. National Development Plan 2007-2013: Transforming Ireland - a Better Quality of Life for All. Dublin: The Stationery Office.

Druckman, A., and T. Jackson. 2009. "The Carbon Footprint of UK Households 1990-2004: A Socio-economically Disaggregated, Quasi-multi-regional Input-Output Model." Ecological Economics 68 (7): 2066-2077.

Elshkaki, A., E. van der Voet, V. Timmermans, and M.V. Holderbeke. 2005. "Dynamic Stock Modelling: A Method for the Indentification and Estimation of Future Waste Streams and Emissions Based on Past Production and Product Stock Characteristics." Energy 30: $1353-1363$.

Eurostat. 2001. Economy-Wide Material Flow Accounts and Derived Indicators: A Methodological Guide. Luxembourg: Eurostat.

Færge, J., J. Magid, and F.W.T.P. Vries. 2001. "Urban Nutrient Balance for Bangkok.” Ecological Modelling 139: 63-74. 
Fischer-Kowalski, M., F. Krausmann, S. Giljum, S. Lutter, A. Mayer, S. Bringezu, Y. Moriguchi, H. Schütz, H. Schandl, and H. Weisz. 2011. "Methodology and Indicators of Economy-Wide Material Flow Accounting State of the Art and Reliability Across Sources." Journal of Industrial Ecology 15 (6): 855-876.

FoE (Friends of the Earth). 2006. A New National Climate Change Strategy for Ireland. Friends of the Earth's Submission to the Government's Review of the Climate Change Policy. Dublin: Friends of the Earth.

Geertman, S., and J. Stillwell, eds. 2003. Planning Support Systems in Practice. Berlin: SpringerVerlag.

Gilbert, R., D. Stevenson, H. Giradet, and S. Stren, eds. 1996. Making Cities Work: The Role of Local Authorities in an Urban Environment. London: Earthscan.

Goldstein, B, M. Birkved, M. Quitzau, and M. Hauschild. 2013. "Quantification of Urban Metabolism Through Coupling with the Life Cycle Assessment Framework: Concept Development and Case Study. Environmental Research Letters 8. 1-14

Grimm, N.B., S.H. Faeth, N.E. Golubiewski, C.L. Redman, J. Wu, X. Bai, and J.M. Briggs; 2008. "Global Change and the Ecology of Cities." Science 319 (5864): 756-760.

Haberl, H., K.H. Erb, V. Gaube, S. Gingrich, and S.J. Singh. 2013. "Socioeconomic Metabolism and the Human Appropriation of Net Primary Production: What Promise Do They Hold for LTSER?" Chap. 2 in Long Term Socio-ecological Research. Human-Environment Interactions 2, edited by Singh, S.J., H. Haberl, M. Chertow, M. Mirtl, and M. Schmid.

Q13 Dordrecht: Springer Science+Business Media.

Haberl, H., M. Fischer-Kowalski, F. Krausmann, H. Weisz, and V. Winiwarter. 2004. "Progress Towards Sustainability: What the Conceptual Framework of Material and Energy Flow Accounting (MEFA) Can Offer." Land Use Policy 21: 199-213.

Harris, B., and M. Batty. 1993. "Locational Models, Geographic Information and Planning Support Systems". Journal of Planning Education and Research 12: 184-198.

Hoggart, K. 2003. "England". Chap. 10 in Housing in the European Countryside: Rural Pressure and Policy in Western Europe, edited by Gallent, N., D.M. Shucksmith, and M. Tewdwr-Jones, London: Routledge.

Huang, S., and W. Hsu. 2003. "Materials Flow Analysis and Energy Evaluation of Taipei's Urban Construction." Landscape and Urban Planning 63: 61-74.

Kemp, R., S. Parto, and R.B. Gibson. 2005. "Governance for Sustainable Development: Moving from Theory to Practice." International Journal of Sustainable Development 8 (1/2): 12-30.

Kennedy, C., J. Cuddihy, and J. Engel-Yan. 2007. "The Changing Metabolism of Cities." Journal of Industrial Ecology 11 (2): 43-59.

750 Kennedy, C., S. Pincetl, and P. Bunje. 2011. "The Study of Urban Metabolism and Its Applications to Urban Planning and Design.” Environmental Pollution 159 (8): 1965-1973.

Kibert, C.J., Jan Sendzimir, and Brad Guy. 2000. "Construction Ecology and Metabolism: Natural System Analogues for a Sustainable Built Environment." Construction Management and Economics 18 (8): 903-916.

Kildare CC (Kildare County Council). 2005. Kildare County Development Plan 2005-2011, Vol. 1. Kildare: Kildare CC.

Kildare CC (Kildare County Council). 2011. Kildare County Development Plan 2011-2017. Kildare: Kildare CC.

Kytzia, S. 2000. "Benefits of Multi-stage MFA-Models in Regional Resource Management." Workshop of the SCOPE-Project MFAStorm, Wuppertal, November 22-24.

Maguire, C., R. Curry, and A. McClenaghan. 2008. Northern Visions - Footpaths to Sustainability. Belfast: Sustainability and Resources Institute (SRI).

Müller, D.B. 2005. "Stock Dynamics for Forecasting Material Flows: Case Study for Housing in the Netherlands." Ecological Economics 59: 142-156.

O’Leary, F., M. Howley, and B. O'Gallachóir. 2008. Energy in Residential Sector. 2008 Annual Report. Cork: Sustainable Energy Ireland (SEI) - Energy Policy Statistical Support Unit.

OECD (Organisation for Economic Co-operation and Development). 2003. "Special Session on Material Flow Accounting: Papers and Presentations." Working Group on Environmental

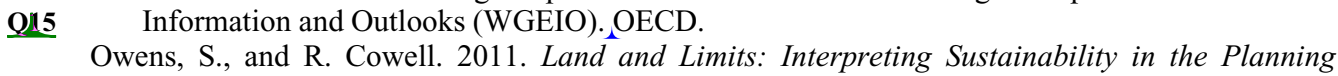
Process. 2nd ed. London: Taylor \& Francis. 
Palmer, J., B. Boardman, C. Bottrill, S. Darby, M. Hinnells, G. Killip, R. Layberry, and H. Lovell; 2006. Reducing the Environmental Impact of Housing. Final Report. Oxford: Environmental Change Institute, University of Oxford.

Putman, S.H, and S.L. Chan. 2001. "The METROPILUS Planning Support System: Urban Models and GIS.' In Planning Support Systems: Integrating Geographic Information Systems, Models and Visualization Tools, edited by R.K. Brail and R.E. Klosterman, 99-128. Redlands, CA: ESRI Press.

Ratti, C., N. Baker, and K. Steemers. 2005. "Energy Consumption and Urban Texture.” Energy and Buildings 37: 762-776.

RoI (Republic of Ireland). 2003. Ireland's Third National Communication Under the United

Q16 Nations Framework Convention on Climate Change. Dublin: RoI.

Roy, M., and G. Ellis. 2010. "The Role of Cross-Disciplinary Models in Reducing the Intensity of Environmental Release - as Example of the Irish Housing Sector." Chap. 2 in Interdisciplinary Aspects of Climate Change, edited by W.L. Filho and F. Mannke. Frankfurt: Peter Lang.

Roy, M., G. Ellis, and R. Curry. 2010. Spatial Allocation of Material Flow Analysis: A Geographic Information System Application of Material Flow Analysis in Ireland. Dublin: Irish Environmental Protection Agency (EPA).

Rylatt, R.M., S.J. Gadsden, and K.J. Lomas. 2003. "Methods of Predicting Urban Domestic Energy Demand with Reduced Datasets: A Review and a New GIS-Based Approach". Building Services Engineering Research and Technology 24: 93-102.

Schiller, G. 2007. "Urban Infrastructure: Challenges for Resource Efficiency in the Building Stock." Building Research \& Information 35: 399-411.

Sinclair, P., E. Papathanasopoulou, W. Meller, and T. Jackson. 2005. "Towards an Integrated Regional Materials Flow Accounting Model.” Journal of Industrial Ecology 9: 69-84.

Srinivasan, S., L.R. O'Fallon, and A. Dearry. 2003. "Creating Healthy Communities, Healthy Homes, Healthy People: Initiating a Research Agenda on the Built Environment and Public Health". American Journal of Public Health 93: 1446-1450.

Swyngedouw, E. 2006. "Circulations and Metabolisms: (Hybrid) Natures and (Cyborg) Cities." Science as Culture 15 (2): 105-121.

Tanikawa, N., N. Lawson, S. Hashimoto, and Y. Moriguchi. 2005. "Spatial Estimation and Visualisation of Regional MFA with GIS Mapping". Industrial Ecology for a Sustainable Future (ISIE) 2005 Conference, Stockholm, June 12-15.

US DoE (U.S. Department of Energy). 2008. Energy Efficiency Trends in Residential and Commercial Buildings. Energy Efficiency and Renewable Energy: US DoE.

Wiedmann, T., and J. Barrett. 2005. The Use of Input-Output Analysis in REAP to Allocate Ecological Footprints and Material Flows to Final Consumption Categories. Report No 2. York: Stockholm Environment Institute.

Wolman, A. 1965. “The Metabolism of Cities". Scientific American 213 (3): 179-190.

Xiang, W.N., and K.C. Clarke. 2003. "The Use of Scenarios in Land Use Planning." Environment Q17 and Planning B: Planning and Design 30:885=909.

Yeo, I.A., S.H. Yoon, and J.J. Yee. 2013. "Development of an Environment and Energy Geographical Information System (E-GIS) Construction Model to Support Environmentally Friendly Urban Planning." Applied Energy 104: 723-739.

815 Yohanis, Y.G., and B. Nortonne. 2002. "Life-Cycle Operational and Embodied Energy for Generic Single-Storey Office Building in the UK." Energy 27: 77-92.

Zhang, Y. 2013. "Urban Metabolism: A Review of Research Methodologies." Environmental Pollution 11 p. (Published online before print). 